\title{
FORMULASI SEDIAAN GEL SCRUB WAJAH SERBUK BIJI KOPI ARABIKA (Coffee arabica) DENGAN KONSENTRASI KARBOPOL 940 SEBAGAI GELLING AGENT
}

\author{
Natasha Faruqi Andrian Putri ${ }^{1 *}$, Desy Nawangsari ${ }^{1}$, Sunarti ${ }^{1}$ \\ ${ }^{1}$ Universitas Harapan Bangsa, Purwokerto \\ *corresponding author \\ Email: natashafaruqi5@gmail.com
}

Diterima : 16 September 2021

Direvisi : 19 Oktober 2021

Publikasi : 20 Oktober 2021

doi:10.52216/jfsi.vol4no2p68-73

\begin{abstract}
Arabica coffee beans contain antioxidants that can provide benefits, one of which is preventing cell damage due to exposure to free radicals. Arabica coffee was formulated as a scrub gel and gelling agent carbopol 940. The purpose of this study was to determine the best concentration of gelling agent for the physical properties and stability of the scrub gel of Arabica coffee beans, and whether or not it would cause irritation when used. Pure experimental research method to determine the effect of a particular treatment by comparing it with a control group that has not received any treatment. Evaluation of gel scrub preparations included evaluation of the physical quality of the preparation and irritation test on 3 rabbits. The results of the evaluation of the preparations showed that all gel scrub formulations were in the form of gel, black particles, distinctive odor, homogeneous, stable after 6 cycles, pH (4.5-7.8), adhesion (2-300 seconds), dispersibility (5 -7 cm). and viscosity (2000-4000 cp), caused a slight skin irritation reaction in the rabbit irritation test. The results of the statistical test of one-way analysis of variance showed that there was a significant difference between the formulas, with a significant value ( $p<0.05)$. However, inventories can still be said to be stable because they are still within the required range. In short, the resulting exfoliating gel has good physical properties and causes little irritation to the skin reaction. Arabica coffee bean powder can be formulated into gel scrub preparations with good physical properties. The concentration in formula IV is carbopol 940 2\%. And stable after 6 cycles of storage
\end{abstract}

Keywords: arabica coffee, gel scrub, gelling agent, karbopol 940

\section{Intisari}

Biji kopi arabika mengandung antioksidan yang dapat memberikan manfaat, salah satunya mencegah kerusakan sel akibat paparan radikal bebas. Kopi arabika diformulasikan sebagai scrub gel dan gelling agent karbopol 940. Tujuan penelitian ini untuk mengetahui konsentrasi gelling agent terbaik untuk sifat fisik dan stabilitas scrub gel biji kopi arabika, serta apakah akan menyebabkan iritasi atau tidak saat digunakan. Metode penelitian eksperimental murni untuk mengetahui pengaruh perlakuan tertentu dengan membandingkannya dengan kelompok kontrol yang belum mendapat perlakuan apa pun. Evaluasi sediaan gel scrub meliputi evaluasi kualitas fisik sediaan dan uji iritasi pada 3 ekor kelinci. Hasil evaluasi sediaan menunjukkan bahwa semua formulasi gel scrub adalah berbentuk gel, partikel hitam, bau khas, homogen, stabil setelah 6 siklus, pH (4,5-7,8), daya lekat (2-300 detik), daya sebar (5-7 $\mathrm{cm}$ ), dan viskositas (2000-4000 cp), menyebabkan reaksi iritasi kulit ringan pada uji iritasi kelinci. Hasil uji statistik analisis varians satu arah menunjukkan bahwa terdapat perbedaan yang signifikan 
antar formula, dengan nilai signifikan (p<0,05). Namun persediaan masih dapat dikatakan stabil karena masih dalam kisaran yang dibutuhkan. Singkatnya, gel pengelupasan yang dihasilkan memiliki sifat fisik yang baik dan menyebabkan sedikit iritasi pada reaksi kulit. Serbuk biji kopi arabika dapat diformulasikan menjadi sediaan gel scrub dengan sifat fisik yang baik Konsentrasi pada formula IV adalah karbopol 940 2\%. Dan stabil setelah 6 siklus penyimpanan.

Kata kunci: gel scrub, gelling agent, karbopol 940, kopi arabika

\section{Pendahuluan}

Kosmetik merupakan produk yang digunakan untuk membersihkan dan memperindah kulit (BPOM, 2015). Salah satu contoh kosmetik yang sering digunakan adalah bentuk gel scrub. Gel scrub merupakan pembersih wajah dengan metode pengelupasan sel - sel kulit mati agar menjadikan kulit tidak kusam dan lebih halus (Decksuler dan Graber, 2012). Gel lebih stabil dan juga dapat memberikan pelepasan terkontrol daripada semi padat lainnya seperti krim, salep, pasta dan lain lain (Rathod dan Metha, 2015).

Kandungan kafein pada kopi dapat menjadikan kulit lembab sehingga terasa lebih halus dan kencang (Zuhaidi, 2019). Menurut penelitian yang dilakukan oleh Aglawe et al. (2019) gel scrub wajah yang diformulasi dengan menggunakan poliherbal sebagai agen pengelupasan menghasilkan sediaan yang memiliki sifat fisik yang baik dan tidak menyebabkan iritasi kulit.

Biji kopi arabika mengandung antioksidan yang dapat memberikan manfaat salah satunya mencegah kerusakan sel akibat paparan radikal bebas (Patay et al., 2016). Kopi arabika dengan konsentrasi $2 \%$ menunjukkan agen pengelupasan yang baik dan tidak mengiritasi kulit serta memperbaiki penampilan kulit tanpa efek samping (Grace et al., 2018).

Keunggulan karbopol sebagai pembentuk gel adalah dapat bercampur dengan banyak zat aktif, dapat diterima, memiliki tampilan organoleptis yang menarik, dan memiliki viskositas yang tinggi pada konsentrasi rendah (Samala dan Sridevi, 2016). Dibandingkan dengan gel yang menggunakan matriks aerosil, gel yang menggunakan matriks karbopol 940 memiliki stabilitas fisik yang lebih baik (Amin, 2014).

Formulasi gel terdiri dari zat aktif, bahan pembentuk gel dan bahan tambahan lainnya
(Sanghi dan Tiwle, 2016). Pemilihan bahan dasar mempengaruhi karakteristik gel yang terbentuk (Sudjono dan Pratimasari, 2012). Dalam penelitian ini diformulasikan gel scrub wajah berbasis karbopol 940.

Keunggulan karbopol adalah tidak beracun, tidak menyebabkan iritasi, dapat digunakan kembali, cocok untuk formulasi gel (Rowe et al., 2017). karbopol dapat digunakan sebagai pengental, surfaktan dan stabilizer. Dalam sediaan kosmetik, karbomer digunakan dalam bentuk netral pada $\mathrm{pH}$ 7,7 karena karbomer stabil pada $\mathrm{pH}$ ini dan karbomer tidak kompatibel dengan asam kuat (Rowe et al., 2017).

Konsentrasi gelling agent harus dipilih dengan tepat sebagai salah satu parameter penentu yang dapat mempengaruhi sifat dan stabilitas fisik gel karena dapat mempengaruhi absorbsi zat aktif pada kulit (Sudjono, dan Pratimasari, 2012). Sehingga diperlukan uji evaluasi formula untuk mengetahui konsentrasi karbopol 940 sebagai gelling agent yang baik pada sediaan gel scrub wajah serbuk biji kopi arabika (Coffee arabica) diamati dari sifat fisik dan uji iritasi.

\section{Metode Penelitian}

Biji kopi arabika (Coffee arabica) diperoleh dari desa Pagentan, kab. Banjarnegara Determinasi kopi arabika dilakukan di Laboratorium Biologi Farmasi, Fakultas Farmasi, Universitas Muhammadiyah Purwokerto.

\subsection{Rancangan Penelitian}

Pengolahan biji kopi arabika dilakukan secara sortasi kering kemudian disangrai sampai berwarna kecokelatan kemudian ditumbuk dan diayak hingga menjadi serbuk halus. Tahap berikutnya dilakukan pembuatan sediaan masker gel scrub dengan konsentrasi karbopol 940 0,5\%, $1 \%, 1,5 \%$ dan $2 \%$. 
Pembuatan gel scrub menggunakan karbomer sebagai basis gel, propilen glikol sebagai humektan, propil paraben sebagai pengawet, trietanolamin sebagai penstabil gel, dan hidrat sebagai pelarut. Kemudian melakukan uji evaluasi, meliputi uji organoleptis, $\mathrm{pH}$, homogenitas, viskositas, daya lekat, dan daya sebar. Kemudian menggunakan metode siklus beku-cair untuk pengujian stabilitas, pada suhu lemari es $5^{\circ} \pm 2^{\circ} \mathrm{C}$ selama 12 hari atau 6 siklus selama 24 jam, selanjutnya ditempatkan pada suhu $40^{\circ} \mathrm{C}$ selama $24 \mathrm{jam}$.

\subsection{Analisis Data}

Analisis data menggunakan KolmogorovSmirnov untuk melihat data terdistribusi normal atau tidak. Jika data terdistribusi normal dan homogen maka dilanjutkan dengan uji analisis varians (Anova) satu arah dengan tingkat kepercayaan 95\% sehingga dapat dilihat apakah perbedaan yang diperoleh signifikan. Jika terdapat perbedaan yang signifikan, maka dilanjutkan dengan uji Beda Nyata Terkecil (BNT) untuk melihat perbedaan antara masing-masing kelompok perlakuan (Besral, 2010). Gunakan program SPSS untuk analisis data dan rate berdasarkan rata-rata persen penekanan edema yang terjadi pada kelompok hewan percobaan.

\section{Hasil dan Pembahasan}

Menurut hasil determinasi Laboratorium Biologi Farmasi, Fakultas Farmasi Universitas Muhammadiyah Purwokerto, bahan utama yang akan digunakan dalam penelitian ini adalah kopi arabika.

Pembuatan gelling agent yaitu menimbang karbopol 940, propil paraben, trietanolamin dan propilen glikol sesuai dengan jumlahnya. Kemudian larutkan propil paraben dalam campuran pelarut yaitu sedikit bagian air dan propilen glikol (Bagian A). Tambahkan karbopol sebanyak $20 \mathrm{ml}$ akuades dan biarkan selama 24 jam agar terjadi pengembangan karbopol 940 yang optimal dan tambahkan trietanolamin sedikit demi sedikit sambil diaduk sampai diperoleh $\mathrm{pH}$ 5,0 hingga 5,5 (Bagian B). Kemudian campurkan Bagian A dan Bagian B.

Setelah terbentuk massa gel yang baik tambahkan serbuk biji kopi arabika (Coffee arabica) aduk sampai homogen (Dantas et al., 2016). Selanjutnya, dilakukan evaluasi sediaan fisik maupun stabilitasnya.

Tabel 1. Formulasi Sediaan Masker Gel Scrub

\begin{tabular}{lccccl}
\hline \multirow{2}{*}{ Bahan } & \multicolumn{4}{c}{ Konsentrasi \% } & \multirow{2}{*}{ Fungsi Bahan } \\
\cline { 2 - 5 } & F1 & F2 & F3 & F4 & \\
\hline $\begin{array}{l}\text { Serbuk Biji kopi } \\
\text { arabika }\end{array}$ & 2 & 2 & 2 & 2 & Bahan Aktif \& \\
Karbopol 940 & 0,5 & 1 & 1,5 & 2 & Gelling agent \\
Propil Paraben & 0,1 & 0,1 & 0,1 & 0,1 & Pengawet \\
Trietanolamin & 2 & 2 & 2 & 2 & Stabilisator gel \\
Propilen glikol & 2 & 2 & 2 & 2 & Humektan \\
Akuades & 65 & 65 & 65 & 65 & Pelarut \\
& $\mathrm{ml}$ & $\mathrm{ml}$ & $\mathrm{ml}$ & $\mathrm{ml}$ & \\
\hline
\end{tabular}

Dari hasil uji organoleptis formula semua formulasi gel dengan perbandingan konsentrasi dan setiap basis yang ada menunjukkan bahwa tidak ada perubahan yang signifikan pada pengamatan sebelum dan sesudah penyimpanan. Artinya, memiliki karakteristik bau kopi, berwarna hitam dan tekstur butiran halus, menunjukkan bahwa pengamatan pada parameter ini stabil sebelum dan sesudah penyimpanan, atau bahan formulasi tidak mengalami reaksi antara satu bahan dengan bahan lainnya selama penyimpanan, sehingga tidak ada tanda-tanda

Tabel 2. Hasil uji organoleptik sediaan gel scrub

\begin{tabular}{ccccc}
\hline Waktu & Formula 1 & Formula 2 & Formula 3 & Formula 4 \\
\hline Siklus ke 0- Siklus & Warna hitam, bau khas & Warna hitam, bau khas & Warna hitam, bau khas & Warna hitam, bau khas \\
1 & $\begin{array}{c}\text { kopi, tekstur gel sedikit } \\
\text { cair, terdapat butiran } \\
\text { halus }\end{array}$ & $\begin{array}{c}\text { kopi, tekstur gel sedikit } \\
\text { kental, terdapat butiran } \\
\text { halus }\end{array}$ & $\begin{array}{c}\text { kopi, tekstur gel sedikit } \\
\text { kental, terdapat butiran } \\
\text { halus }\end{array}$ & $\begin{array}{c}\text { kental, terdapat butiran } \\
\text { halus }\end{array}$ \\
\hline
\end{tabular}

Keterangan:

Formula I

Formula II

Formula III

Formula IV
: gel scrub biji kopi arabika (Coffee arabica) dengan konsentrasi karbopol 940 0,5\%

: gel scrub biji kopi arabika (Coffee arabica) dengan konsentrasi karbopol 940 1\%

: gel scrub biji kopi arabika (Coffee arabica) dengan konsentrasi karbopol 940 1,5\%

: gel scrub biji kopi arabika (Coffee arabica) dengan konsentrasi karbopol 940 2\% 
merespons perubahan warna, tekstur, dan bau.

Dari hasil uji $\mathrm{pH}$ sediaan gel Dari hasil $\mathrm{pH}$ sediaan gel scrub, hasil pengujian menunjukkan bahwa perubahan konsentrasi karbopol 940 tidak berpengaruh terhadap perubahan nilai $\mathrm{pH}$ gel. Formula 1, 2, 3, 4 memiliki nilai $\mathrm{pH}$ yang sesuai dengan rentang persyaratan secara SNI No. 062588 yaitu 4,5-7,8. Jika kisaran $\mathrm{pH}$ sediaan topikal tidak sesuai dengan $\mathrm{pH}$ kulit, sediaan dapat menyebabkan iritasi dan eritema pada pengguna (Izzati, 2014).

Tabel 3. Hasil Uji Homogenitas Sediaan

\begin{tabular}{ccccc}
\hline Waktu & Formula & Formula & Formula & Formula \\
& $\mathbf{1}$ & $\mathbf{2}$ & $\mathbf{3}$ & $\mathbf{4}$ \\
\hline Siklus 0 & Homogen & Homogen & Homogen & Homogen \\
Siklus 1 & Homogen & Homogen & Homogen & Homogen \\
Siklus 2 & Homogen & Homogen & Homogen & Homogen \\
Siklus 3 & Homogen & Homogen & Homogen & Homogen \\
Siklus 4 & Homogen & Homogen & Homogen & Homogen \\
Siklus 5 & Homogen & Homogen & Homogen & Homogen \\
Siklus 6 & Homogen & Homogen & Homogen & Homogen \\
\hline
\end{tabular}

Keterangan :

Formula I : gel scrub biji kopi arabika (Coffee arabica) dengan konsentrasi karbopol 940 $0,5 \%$

Formula II : gel scrub biji kopi arabika (Coffee arabica) dengan konsentrasi karbopol $9401 \%$

Formula III : gel scrub biji kopi arabika (Coffee arabica) dengan konsentrasi karbopol 940 1,5\%

Formula IV : gel scrub biji kopi arabika (Coffee arabica) dengan konsentrasi karbopol 940 2\%

Berdasarkan hasil uji homogenitas, perubahan konsentrasi karbopol 940 tidak berpengaruh terhadap homogenitas gel. Hasil penelitian (Natsir, 2012) menunjukkan bahwa sediaan homogen karena keseragaman ukuran partikel gel dan daya lekat sediaan. Jika formulasinya homogen, aplikasinya akan lebih mudah.

Pemeriksaan viskositas dilakukan dengan menggunakan viskometer Atago, dengan kecepatan yang sama yaitu $30 \mathrm{rpm}$. Dilihat dari hasil uji viskositas, menunjukkan bahwa semakin tinggi konsentrasi karbopol 940, maka akan meningkatkan nilai viskositas, sehingga tingkat kekentalan suatu sediaan semakin tinggi pula karena jumlah polimer yang akan membentuk basis gel semakin banyak. Semakin tinggi konsentrasi karbopol 940 maka jumlah polimer semakin banyak (Suhaime 2012).

Pengujian daya lekat gel scrub dilakukan untuk mengetahui seberapa lekat waktu yang dibutuhkan gel agar dapat melekat pada permukaan kulit. Semakin lama daya lekat formulasi gel maka semakin baik formulasi gel tersebut, karena semakin banyak zat aktif yang dapat berdifusi ke dalam kulit maka semakin baik efek yang dapat diperoleh (Pujiastuti dan Kristiani, 2019).

Uji daya sebar dilakukan untuk mengetahui kemampuan sediaan untuk menyebar saat dioleskan pada kulit (Subaidah et al., 2020). Daya sebar yang baik untuk sediaan topikal kulit wajah adalah 5-7 cm (Garg et al., 2002).

Uji iritasi akut dermal merupakan salah satu rangkaian uji toksisitas yang dilakukan pada hewan coba (kelinci albino) untuk mendeteksi efek toksik yang terjadi setelah terpapar preparat uji (BPOM, 2014).

Tabel 4. Pengamatan Sediaan Uji Iritasi

\begin{tabular}{ccccccc}
\hline & \multicolumn{3}{c}{$\begin{array}{c}\text { Jumlah skor } \\
\text { eritema \& udema }\end{array}$} & \multicolumn{3}{c}{ Skor PII } \\
\cline { 2 - 7 } Sediaan & $\mathbf{R 1}$ & $\mathbf{R 2}$ & $\mathbf{R 3}$ & $\mathbf{R} 1$ & $\mathbf{R 2}$ & $\mathbf{R 3}$ \\
& $(\mathbf{E}+\mathbf{U})$ & $(\mathbf{E}+\mathbf{U})$ & $(\mathbf{E}+\mathbf{U})$ & & & \\
\hline F0 & 1 & 1 & 1 & 0,0 & 0,0 & 0,0 \\
F1 & 1 & 1 & 1 & 0,0 & 0,0 & 0,0 \\
F2 & 1 & 1 & 1 & 0,0 & 0,0 & 0,0 \\
F3 & 1 & 1 & 1 & 0,0 & 0,0 & 0,0 \\
F4 & 1 & 1 & 1 & 0,0 & 0,0 & 0,0 \\
KS & 0 & 0 & 0 & 0,0 & 0,0 & 0,0 \\
\hline
\end{tabular}

Keterangan :

Formula I : gel scrub biji kopi arabika (Coffee arabica) dengan konsentrasi karbopol 940 $0,5 \%$

Formula II : gel scrub biji kopi arabika (Coffee arabica) dengan konsentrasi karbopol $9401 \%$

Formula III : gel scrub biji kopi arabika (Coffee arabica) dengan konsentrasi karbopol 940 1,5\%

Formula IV : gel scrub biji kopi arabika (Coffee arabica) dengan konsentrasi karbopol $9402 \%$

K Sehat : Kontrol normal yaitu tanpa diberi perlakuan apa pun 

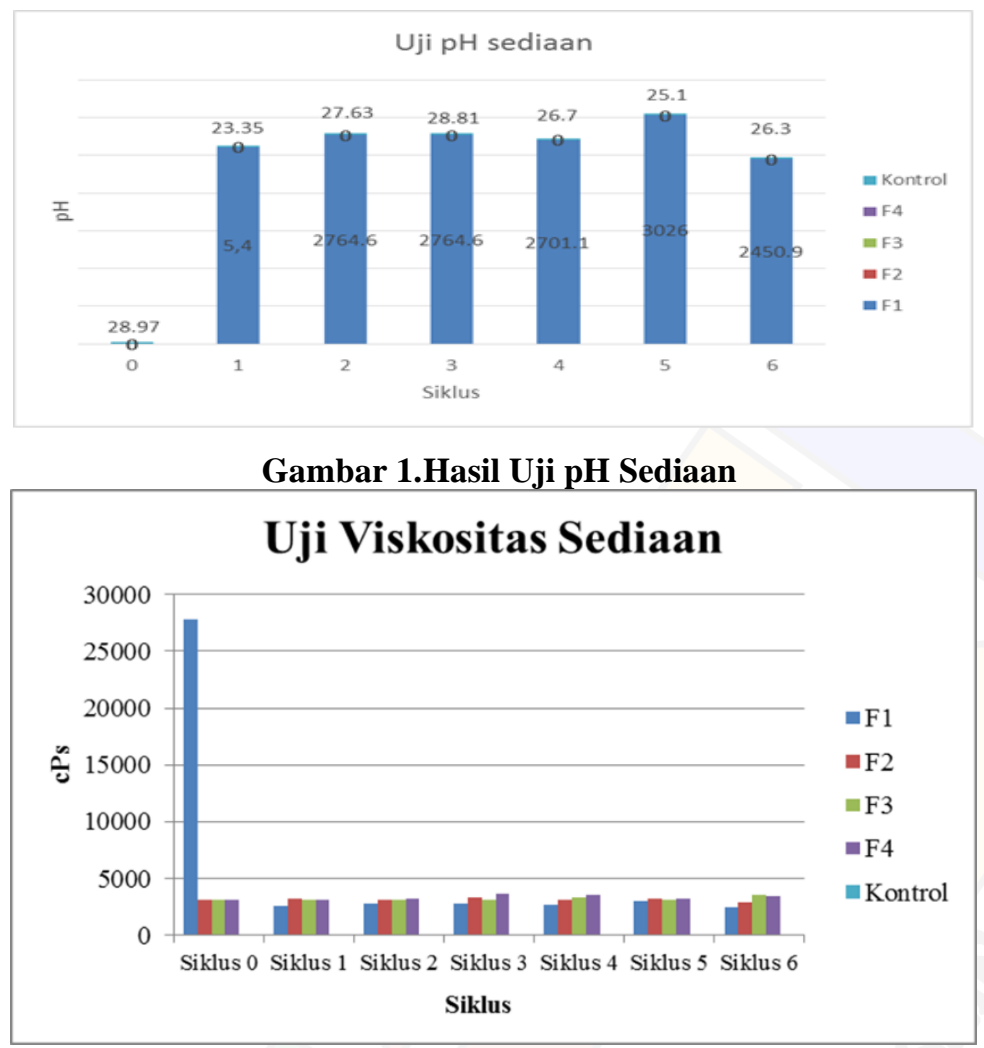

Gambar 2. Hasil Uji Viskositas Sediaan

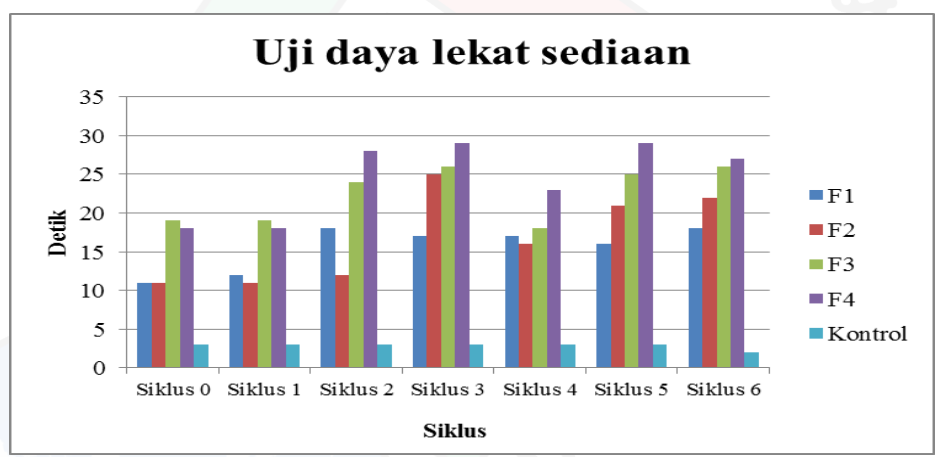

Gambar 3. Hasil Daya Lekat Sediaan

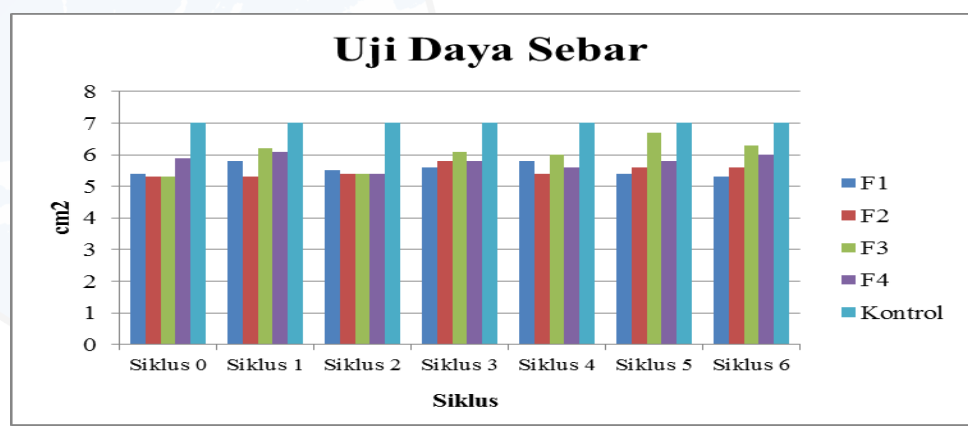

Gambar 4. Hasil Uji Daya Sebar

Keterangan :

Formula I

Formula II

Formula III

Formula IV
: gel scrub biji kopi arabika (Coffee arabica) dengan konsentrasi karbopol 940 0,5\% : gel scrub biji kopi arabika (Coffee arabica) dengan konsentrasi karbopol 940 1\% : gel scrub biji kopi arabika (Coffee arabica) dengan konsentrasi karbopol 940 1,5\% : gel scrub biji kopi arabika (Coffee arabica) dengan konsentrasi karbopol $9402 \%$ 


\section{Kesimpulan}

Konsentrasi karbopol 940 yang terbaik terhadap sifat fisik dan stabilitas sediaan gel srub wajah serbuk biji kopi arabika (coffee arabika) yaitu formula IV dengan konsentrasi karbopol 940 $2 \%$. Dilihat dari parameter viskositas dan daya lekat. Dengan rentang pH 5,0-6,8, daya sebar 5,3$6,13 \mathrm{~cm}$, daya lekat 18-29 detik, viskositas 31453675 cPs. Formula gel $s r u b$ wajah serbuk biji kopi arabika (coffee arabika) dengan gelling agent karbopol 940 menyebabkan reaksi kulit dengan skor iritasi sangat ringan.

\section{Daftar Pustaka}

Amin, J. E. (2014) Pengaruh Jenis Dan Konsentrasi Basis Sediaan Gel Ekstrak Daun Botto'-Botto' ((Chromolaena Adorata (L)) Sebagai Obat Luka Terhadap Stabilitas Fisik Sediaan. Universitas Alaudin Makassar.

BPOM (2014) 'Uji Toksisitas. Non Klinik. In Vivo. Pedoman', 8(33), p. 44.

BPOM (2015) 'Persyaratan Teknis Kosmetika', Nomor HK, 3(23.08)

Dantas, M.G. B. Silvio A.G.B, Camila M.D.D, Larissa A.R, 1 Pedro J.R.N, Ferdinando A.C, Lucindo J.Q.J, Jackson R. G (2016) 'Development and Evaluation of Stability of a Gel Formulation Containing the Monoterpene Borneol', Scientific World Journal Volume 2016. doi: $10.1155 / 2016 / 7394685$

Desy Nawangsari., 2019. Pengaruh Bahan Pengisi Terhadap Massa Cetak Tablet Vitamin C, Jurnal Kesehatan, Kebidanan, Keperawatan.

Garg, A. Deepika Aggarwal, a. k. Singla., 2002. 'Spreading of Semisolid Formulations: An Update', Pharmaceutical Technology North America, 26(9), pp. 84-105.

Fenny Indah Safitri., Desy Nawangsari., Dina Febrina., 2020. Overview: Application of Carbopol 940 in Gel. Advances in Health Sciences Research, volume 34.

Izzati, M. K. (2014) 'Formulasi dan Uji Aktivitas Antioksidan Sediaan Masker Peel Off Ekstrak Etanol 50\% Kulit Buah Manggis (Garcinia mangostana L.). Skripsi',
2014(August), pp. 1-43. Available at: http://dx.doi.org/10.1016/j.scitotenv.2014.10. 007.

Maria Asumta Nogo Amuntoda. 2018. 'Perbandingan Kadar Alkohol Dan Uji Organoleptik WineKopi Arabika (Coffea Arabica) Temanggung Varietas Kartika yang dihasilkan melalui metode ekstraksi cold brewdan maserasi menggunakan strain yeast polandia (Saccharomyces cereviceae). Universitas Sanata Dharma Yogyakarta

Natsir, N. H. (2012) 'Pengaruh Jenis Pengikat Terhadap Sifat Fisika Sediaan Serbuk Masker Wajah Daun Jambu Biji ( Psidium Guajava L) Skripsi', Jurnal Biogenesis, pp. 1-86.

Rathod, H. J dan Metha, D. P. (2015)' Acta Scientifica International Journal of Phamaceutical Science', International Journal of Phamaceutical, 1(1), pp. 33-47

Rowe et al. (2017) Handbook of Pharmaceutical aExcipients Eighth Edition. London: Pharmaceutical Press.

Samala, M. L. dan Sridevi,G. (2016)' Role of Polymers as Gelling Agents in the Formulation of Emulgels', Polymer science, 2(1), pp. 1-8,doi:10.4172/2471-9935.100010

Sanghi, D. K. dan Tiwle R. (2016) ' Formulation And Characterization Of Herbal Face Wash/Scruber', European Journal Of Pharmaceutical And Medical Research, 3(11), pp. 274-278.

Sudjono, T. A., Honniasih, M. and Pratimasari, Y. R. (2012) 'the Influence of Carbomer 934 and Hpmc Concentration As Gelling Agent in', Pengaruh Konsentrasi Gelling Agent Carbomer 934 dan HPMC Pada Formulasi Gel Lendir Bekicot (Achatina Fulica) Terhadap Kecepatan Penyembuhan Luka Baka Pada Punggung Kelinci, 13(1), pp. 611.

Suhaime, I. H. B., Tripathy, M., Mohamed, M.S., \& Majeed, A. B. A. (2012). The Pharmaceutical Applications of Carbomer. Asian Journal of Pharmaceutical Sciences and Research, 2(2), 1-12 . 